\title{
Textile-Based Battery Using a Biodegradable Gel-Electrolyte ${ }^{\dagger}$
}

\author{
Sandra Gellner 1,* , Anne Schwarz-Pfeiffer ${ }^{2,3}$ and Ekaterina Nannen ${ }^{1,3}$
}

Citation: Gellner, S.; SchwarzPfeiffer, A.; Nannen, E. Textile-Based Battery Using a Biodegradable Gel-Electrolyte. Proceedings 2021, 68, 17. https://doi.org/10.3390/ proceedings2021068017

Published: 27 January 2021

Publisher's Note: MDPI stays neutral with regard to jurisdictional claims in published maps and institutional affiliations.

Copyright: $₫ 2021$ by the authors. Licensee MDPI, Basel, Switzerland. This article is an open access article distributed under the terms and conditions of the Creative Commons Attribution (CC BY) license (http://creativecommons.org/licenses /by/4.0/).
1 Faculty of Electrical Engineering and Computer Science, Niederrhein University of Applied Sciences, 47805 Krefeld, Germany; ekaterina.nannen@hs-niederrhein.de

2 Faculty of Textile and Clothing Technology, Niederrhein University of Applied Sciences, 41065 Mönchengladbach, Germany; anne.schwarz-pfeiffer@hs-niederrhein.de

3 Textile Innovatory, Niederrhein University of Applied Sciences, 41065 Mönchengladbach, Germany

* Correspondence: sandra.gellner@hs-niederrhein.de

+ Presented at the International Conference on the Challenges, Opportunities, Innovations and Applications in Electronic Textiles (E-Textiles 2020), Virtual venue, UK, 4 November 2020.

\begin{abstract}
Lightweight and flexible batteries with natural gel-electrolyte between textile-based electrodes are presented, demonstrating a discharge capacity of $100 \mathrm{mAh} \mathrm{g}^{-1}$ at $14 \mathrm{~mA} \mathrm{~g}^{-1}$ with respect to the anode. Aging processes of the gel-matrix are investigated, showing that the device can be refreshed by re-wetting the gel-electrolyte. Due to the textile-based architecture, the batteries can be bent up to $180^{\circ}$ with minor influence on the battery voltage.
\end{abstract}

Keywords: textile-based battery; biodegradable electrolyte; textile electronics; low-cost devices

\section{Introduction}

The interest in textile electronics is increasing both in scientific research and in multiple industry sectors, such as medicine and health care, sports, or fashion [1-3]. Therefore, there is a high demand on local textile-based power supplies, which are lightweight, compact in size, flexible and, in addition, exhibit a comfortable haptic. Especially when textile electronics are used in immediate proximity to the human body, the applied materials should be non-toxic and eco-friendly. Various strategies and methods can be implemented in textile electronics systems for the generation and supply of electricity, such as energy harvesting and/or storage. Biomechanical processes [4,5], body heat [6], or solar energy [7] can be exploited as well as, for example, batteries [8] or capacitors [9]. In this contribution we will focus on batteries.

The state-of-the-art batteries incorporate lithium, which might be critical for their use as textile electronic power supplies since the used electrolytes are toxic and flammable. Therefore, a rigorous encapsulation is needed and the downsizing of the batteries including their encapsulation is a tough challenge [10]. Additionally, the low abundance of lithium is problematical [11]. Accordingly, post-lithium batteries are required, which provide non-toxic components with high abundance and thus result in low-cost electronics.

Textile-based batteries can be realized by using coated fabrics stacked together layer by layer or coated fibers, which can be woven to a fabric. In recent years, there have been several developments to realize textile-based batteries with lithium-free electrodes. Especially sodium-based (for example $87 \mathrm{mAh} \mathrm{g}^{-1}$ at $50 \mathrm{~mA} \mathrm{~g}^{-1}$ [12]) and zinc- or aluminum-air batteries (e.g., $542 \mathrm{mAh} \mathrm{gZn}^{-1}$ at $2 \mathrm{~mA} \mathrm{~cm}^{-2}$ [13] or $935 \mathrm{mAh} \mathrm{g}^{-1}$ at $0.5 \mathrm{~mA}$ $\mathrm{cm}^{-2}$ [14]) show promising performances. The yarn-based aluminum air battery was realized with a cathode made of cross-stacked carbon nanotubes (CNT) sheets coated with silver nanoparticles, providing high capacity and also being flexible and even stretchable with an Aluminum spring as an anode [14]. 
Here, we present lightweight and flexible batteries with biodegradable gelelectrolyte sandwiched between textile-based electrodes. The discharge capacity can achieve values of $100 \mathrm{mAh} \mathrm{g}^{-1}$ with respect to the anode. Aging processes of the gel-matrix are investigated. Due to the textile-based architecture, the batteries are flexible and can be bent up to $180^{\circ}$ with minor influence on battery voltage.

\section{Experimental Section}

Figure 1a shows the schematic assembly of the textile-based battery. A natural biopolymer gel-electrolyte is sandwiched between textile-based electrodes. A piece of cotton fabric is used as separator. A commercially available copper fabric is used as a cathode, while Aluminum foil glued on a fabric serves as an anode. Aluminum provides, in contrast to most anode materials used in common batteries, high abundance and high theoretical gravimetric and volumetric capacities [11]. The gel electrolyte is a mixture of citric acid and starch. The chemical structures of those materials are depicted in Figure $1 \mathrm{~b}$. Both materials are biodegradable, soluble in water, and inexpensive. In this assembly, the aluminum as anode is consumed. Integrated in an electrical circuit, aluminum ions and electrons are extracted. The electrons will migrate via an external circuit and the ions via the electrolyte towards the cathode.

(a)

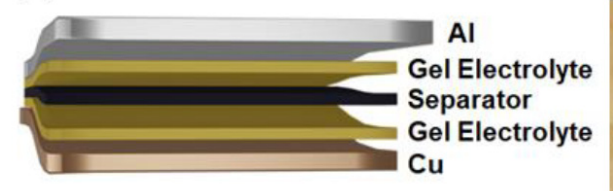

(b) Starch

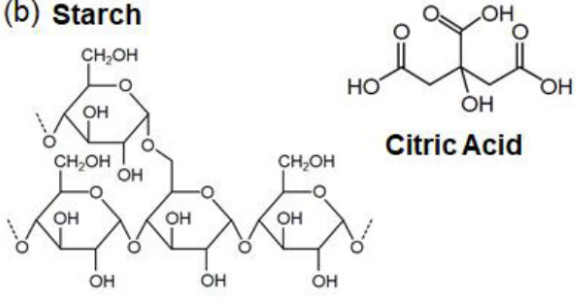

(c)

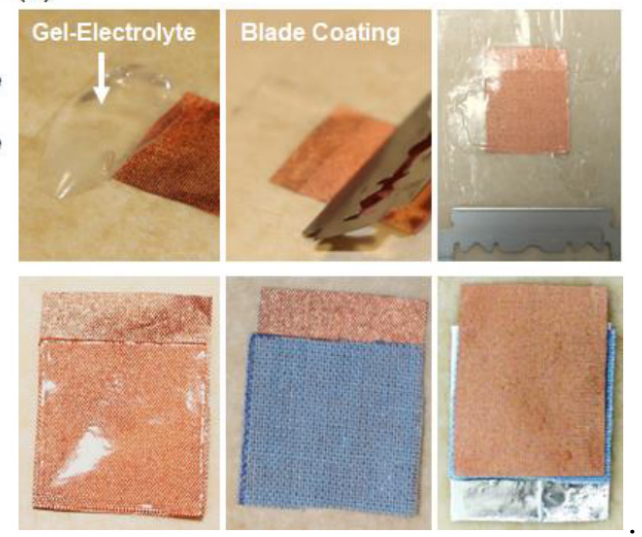

Figure 1. (a) Schematic architecture of textile-based battery, (b) chemical structure of both materials for the gel electrolyte, and (c) the fabrication process of the textile-based battery.

The fabrication process is shown in Figure 1c. The electrodes with a size of $2 \mathrm{~cm} \times 2.5$ $\mathrm{cm}$ are masked with tape, so an area of $2 \times 2 \mathrm{~cm}^{2}$ is accessible and can be coated. The gel electrolyte is prepared by mixing citric acid $(0.2 \mathrm{~mol} / \mathrm{L})$, starch, and distilled water. This mixture is heated until a transparent gel is formed. The gel is coated on both electrodes by blade coating. After removing the tape, the device is stacked together. For the separator, a cotton fabric with a size of $2 \mathrm{~cm} \times 2 \mathrm{~cm}$ is used between the coated electrodes. For the calculation of specific capacity, the mass of the active area of the anode is used ( $=14$ $\mathrm{mg})$.

Two methods for discharging the batteries are used. The first method is discharging with current. Here, the battery is connected to a source/measure unit (Keysight B2902A), which is connected to a PC with LabVIEW program. The discharge current can be set, and the voltage of the battery is measured over time. The second method is discharging the battery with a resistance. In our setup, the voltage is measured with help of a multifunctional I/O device (NI USB-6009), and the current is calculated. The specific capacity is calculated by the measured or set discharge current, the measurement time, and the mass of the active anode area. 


\section{Results and Discussion}

The voltage of the textile-based battery without load is typically around $0.53 \mathrm{~V}$. With the load of $2 \mathrm{k} \Omega$, the operational voltage is lower than $200 \mathrm{mV}$, but stabile for at least seven hours, and a capacity of $47 \mathrm{mAh} \mathrm{g}^{-1}$ is reached. To improve the stability of the gel electrolyte, salt was added to the citric acid/starch mixture. The voltage of the battery without load does not change, while under load the operation voltage doubled (Figure 2a). Moreover, the capacity doubled, reaching a value greater than $90 \mathrm{mAh} \mathrm{g}^{-1}$ after seven hours of operation. The incorporation of salt into the gel electrolyte improved the performance of the battery and the gel became more stable against environmental circumstances like the formation of mildew. Overall, the battery reaches specific capacity of $100 \mathrm{mAh} \mathrm{g}^{-1}$ at $14 \mathrm{~mA} \mathrm{~g}^{-1}$. At a discharge current of $100 \mu \mathrm{A}\left(7 \mathrm{~mA} \mathrm{~g}^{-1}\right)$, the operation voltage of the battery is ca. $0.42 \mathrm{~V}$ and at $200 \mu \mathrm{A}\left(14 \mathrm{~mA} \mathrm{~g}^{-1}\right)$ is ca. $0.29 \mathrm{~V}$. After three hours of operation, the behavior of the battery voltage without load was tested. Within ten minutes of relaxation, the initial voltage is reached depending on discharge current and discharge time. This recovery is limited due to fact that the aluminum anode is consumed during operation.
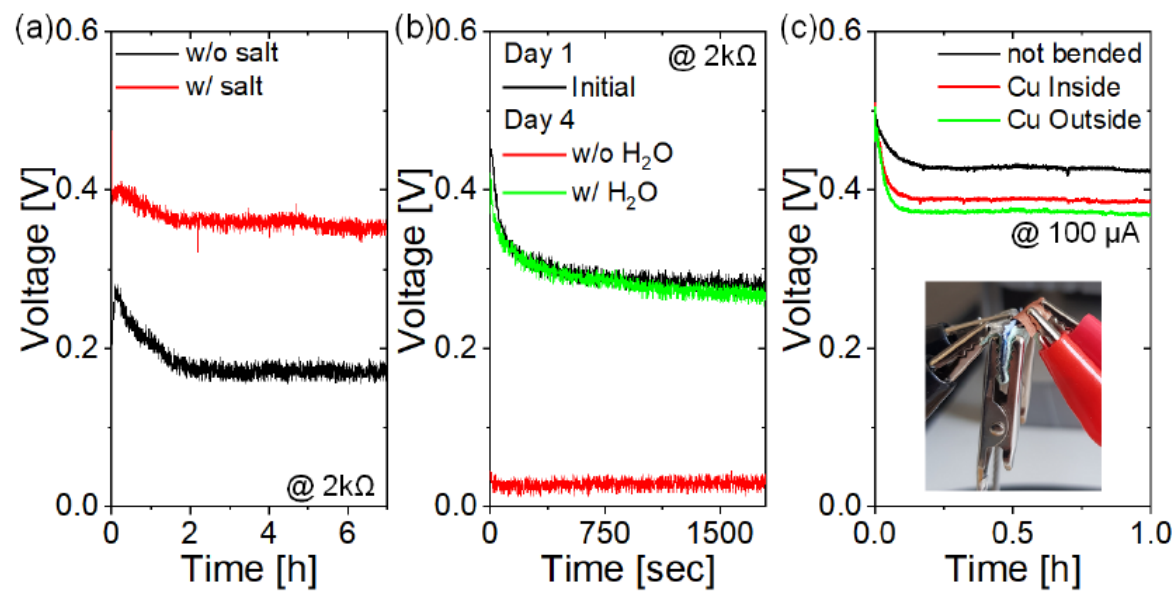

Figure 2. (a) Discharge Curve of textile-based battery with (red line) and without additional salt (black line) in the gel electrolyte at $2 \mathrm{k} \Omega$ resistance. (b) Discharge Curve of textile-based battery on the first day (black line) and fourth day (red line) after fabrication at a load of $2 \mathrm{k} \Omega$. The battery shows, after four days, poor performance; therefore, two drops of water were soaked into the textile separator to improve the performance (green line). (c) Discharge curves of non-bended battery (black line) and $180^{\circ}$ bended battery with copper as inner (red line) and outer (green line) electrode at $100 \mu \mathrm{A}$, with a picture of the bended textile-based battery.

It is interesting to discuss the aging processes, which were investigated and could be mainly attributed to dehydration of the device over time. For example, a battery, which was discharged with $2 \mathrm{k} \Omega$ for a half hour on the first day after production, was again discharged with the same load for the same time period on day four after fabrication, showing poor performance: the operation voltage was below $50 \mathrm{mV}$ (see Figure $2 \mathrm{~b}$ ). The capacity was low as well with $0.6 \mathrm{mAh} \mathrm{g}^{-1}$ in contrast to $5.4 \mathrm{mAh} \mathrm{g}^{-1}$ at initial measurement. After rewetting the battery with just two drops of water, the battery completely recovered and showed the same performance as before. This finding is important: Either a flexible encapsulation is needed, or the application of the battery must be in a wet environment, for example, to indicate moisture. The refreshment of the battery can just occur if aluminum is not completely consumed.

The battery is also tested under bending conditions. In Figure 2c, the discharge curves in bended and not bended states and a picture of the bended battery are shown. While the battery voltage without load does not change, there is a minor influence of the operational voltage ( $91 \%$ and $86 \%$ of voltage in not bending condition) when the battery is discharged 
at $100 \mu \mathrm{A}$. The cotton separator is a physical barrier between the electrodes, so short circuits can be prevented while bending.

\section{Conclusions}

A textile-based battery with a natural, biodegradable, and water-based gelelectrolyte was presented. The discharge capacity can achieve values of $100 \mathrm{mAh} \mathrm{g}{ }^{-1}$ and the battery can be bent up to $180^{\circ}$ with only minor influence on battery voltage. Therefore, it is a promising concept for low-cost, lightweight wearable power supplies.

Supplementary Materials: The following are available online at www.mdpi.com/2504$3900 / 68 / 1 / 17 /$ s1.

Acknowledgments: The authors thank Rainer Kufferath for the helping establishing the measurement setup and Sarah Wossack for valuable discussions. The authors acknowledge the financial support of the University of the Applied Sciences of Niederrhein.

Institutional Review Board Statement: Not applicable.

Informed Consent Statement: Not applicable.

Data Availability Statement: Data is contained within the article or supplementary material. The data presented in the study are available in supplementary material.

Conflicts of Interest: The authors declare no conflict of interest.

\section{References}

1. Weng, W.; Chen, P.; He, S.; Sun, X.; Peng, H. Smart Electronic Textiles. Angew. Chem. Int. Ed. 2016, 55, 6140-6169, doi:10.1002/anie.201507333.

2. Huang, Q.; Wang, D.; Zheng, Z. Textile-Based Electrochemical Energy Storage Devices. Adv. Energy Mater. 2016, 6, 1600783, doi:10.1002/aenm.201600783.

3. Jost, K.; Dion, G.; Gogotsi, Y. Textile energy storage in perspective. J. Mater. Chem. A 2014, 2, 10776, doi:10.1039/c4ta00203b.

4. Chen, X.; Miao, L.; Guo, H.; Chen, H.; Song, Y.; Su, Z.; Zhang, H. Waterproof and stretchable triboelectric nanogenerator for biomechanical energy harvesting and self-powered sensing. Appl. Phys. Lett. 2018, 112, 203902, doi:10.1063/1.5028478.

5. Zhang, M.; Zhao, M.; Jian, M.; Wang, C.; Yu, A.; Yin, Z.; Liang, X.; Wang, H.; Xia, K.; Liang, X.; et al. Printable Smart Pattern for Multifunctional Energy-Management E-Textile. Matter 2019, 1, 168-179, doi:10.1016/j.matt.2019.02.003.

6. Kim, M.-K.; Kim, M.-S.; Lee, S.; Kim, C.; Kim, Y.-J. Wearable thermoelectric generator for harvesting human body heat energy. Smart Mater. Struct. 2014, 23, 105002, doi:10.1088/0964-1726/23/10/105002.

7. Cho, S.H.; Lee, J.; Lee, M.J.; Kim, H.J.; Lee, S.-M.; Choi, K.C. Plasmonically Engineered Textile Polymer Solar Cells for HighPerformance, Wearable Photovoltaics. ACS Appl. Mater. Interfaces 2019, 11, 20864-20872, doi:10.1021/acsami.9b05048.

8. Li, H.; Liu, Z.; Liang, G.; Huang, Y.; Huang, Y.; Zhu, M.; Pei, Z.; Xue, Q.; Tang, Z.; Wang, Y.; et al. Waterproof and Tailorable Elastic Rechargeable Yarn Zinc Ion Batteries by a Cross-Linked Polyacrylamide Electrolyte. ACS Nano 2018, 12, 3140-3148, doi:10.1021/acsnano.7b09003.

9. Meng, Y.; Zhao, Y.; Hu, C.; Cheng, H.; Hu, Y.; Zhang, Z.; Shi, G.; Qu, L. All-Graphene Core-Sheath Microfibers for All-SolidState, Stretchable Fibriform Supercapacitors and Wearable Electronic Textiles. Adv. Mater. 2013, 25, 2326-2331, doi:10.1002/adma.201300132.

10. Yu, P.; Zeng, Y.; Zhang, H.; Yu, M.; Tong, Y.; Lu, X. Flexible Zn-Ion Batteries: Recent Progresses and Challenges. Small 2019, 15, 1804760, doi:10.1002/smll.201804760.

11. Walter, M.; Kovalenko, M.V.; Kravchyk, K.V. Challenges and benefits of post-lithium-ion batteries. New J. Chem. 2020, 44, 16771683, doi:10.1039/C9NJ05682C.

12. Zhu, Y.; Yuan, S.; Bao, D.; Yin, Y.; Zhong, H.; Zhang, X.; Yan, J.; Jiang, Q. Decorating Waste Cloth via Industrial Wastewater for Tube-Type Flexible and Wearable Sodium-Ion Batteries. Adv. Mater. 2017, 29, 1603719, doi:10.1002/adma.201603719.

13. Chen, X.; Liu, B.; Zhong, C.; Liu, Z.; Liu, J.; Ma, L.; Deng, Y.; Han, X.; Wu, T.; Hu, W.; et al. Ultrathin Co 3 O 4 Layers with Large Contact Area on Carbon Fibers as High-Performance Electrode for Flexible Zinc-Air Battery Integrated with Flexible Display. Adv. Energy Mater. 2017, 7, 1700779, doi:10.1002/aenm.201700779.

14. Xu, Y.; Zhao, Y.; Ren, J.; Zhang, Y.; Peng, H. An All-Solid-State Fiber-Shaped Aluminum-Air Battery with Flexibility, Stretchability, and High Electrochemical Performance. Angew. Chem. Int. Ed. 2016, 55, 7979-7982, doi:10.1002/anie.201601804. 